\title{
ADN del diseño de la artesanía como herramienta de desarrollo y apertura de nuevos mercados.
}

\author{
Santamaría-Aguirre, Jorge ${ }^{a}$ y Lecuona-López, Manuel ${ }^{b}$

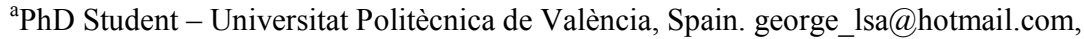 \\ ${ }^{\mathrm{b}} \mathrm{PhD}$. Full Professor - Universitat Politècnica de València, Spain. mlecuona@dib.upv.es.
}

\begin{abstract}
Craft is projected as a productive sector of the Cultural and Creative Industry [CCI] that has great potential in Ecuador, due to positive changes that have taken place in the country in favor of productive development through state policies and planning To improve the productive sectors. As part of the CCI, textile crafts in the province of Tungurahua should seek to promote and exploit the ancestral value and know-how of their products; and through design management must propose strategies of innovation and diversification of products, in addition to its growth and openness to new markets. The research objective is to identify components of a DNA that identifies the craft activity and its particular characteristics in the province of Tungurahua; from a global vision and focus towards cultural and creative endeavors.
\end{abstract}

The research was developed with a qualitative methodology based on the analysis of contents and weighting of important factors of the craft sector and its environment. The contents were compared between perspectives of organizations worldwide such as the United Nations Educational, Scientific and Cultural Organization (UNESCO) and the European Commission; And from Ecuador, through the Productive Transformation Agenda [ATP]. The data were analyzed by means of a triangulation that allowed contrast results and understand the possibilities of integration of the design to improve products, creative and productive processes of the textile handicraft in the Province of Tungurahua.

Throughout the article, key arguments are presented for the construction of factors that constitute the DNA proposal of the design of textile crafts; Whose structure is based on five important components: society and its environment, the cultural and creative dimension, design, business structure and strategy.

Keywords: Crafts, DNA, Design, Enterprise, ICC 


\section{Resumen}

La artesanía se proyecta como un sector productivo de la Industria Cultural y Creativa [ICC] que cuenta con gran potencial en Ecuador, esto debido a cambios positivos que se han dado en el país en favor del desarrollo productivo a través de políticas de estado y la planificación para mejorar los sectores productivos. Como parte de la ICC, la artesanía textil en la Provincia de Tungurahua se debe buscar potenciar y explotar el valor ancestral y saber hacer de sus productos; y, a través de la gestión de diseño debe plantear estrategias de innovación y diversificación de productos, además de su crecimiento y apertura a nuevos mercados. El objetivo de investigación es identificar componentes de un ADN que identifique a la actividad artesanal y sus características particulares en la provincia de Tungurahua; esto, desde una visión global y de enfoque hacia emprendimientos culturales y creativos.

La investigación se desarrolló con una metodología cualitativa basada en el análisis de contenidos y ponderación de factores importantes del sector artesanal y su entorno. Los contenidos se compararon entre perspectivas de organizaciones a nivel mundial como la Organización de las Naciones Unidas para la Educación, la Ciencia y la Cultura [UNESCO] y la Comisión Europea; y desde Ecuador, a través de la Agenda de Transformación Productiva [ATP]. Los datos se analizaron mediante una triangulación que permitió contrastar resultados y comprender las posibilidades de integración del diseño para mejorar productos, procesos creativos y productivos de la artesanía textil en la Provincia de Tungurahua.

A lo largo del artículo se plantean argumentos clave para la construcción de factores que constituyen la propuesta del ADN del diseño de la artesanía textil; cuya estructura se basa en cinco componentes importantes: la sociedad y su entorno, el dimensión cultural y creativa, el diseño, la estructura empresarial y la estrategia.

Palabras clave: ADN, Artesanía, Diseño, Empresa, ICC 


\section{Introducción}

La artesanía como expresión cultural de los pueblos adquiere gran valor histórico y social por sus costumbres, historias y experiencias únicas. El saber hacer propio del artesanado se transforma en un potencial de desarrollo debido a las formas particulares de elaboración, producción y materiales conjugados a través de la creatividad.

Tanto la cultura como la creatividad llevadas a la realidad mediante objetos construidos con hábiles manos, son parte de una cosmovisión propia de un país o región, y hacen que la artesanía se ubique como un sector más de la Industria Cultural y Creativa [ICC] (UNCTAD, 2010; UNESCO, 2011; UNESCO, 2013).

\subsection{Situación de la artesanía en Ecuador}

En Ecuador, país Latinoamericano; está en marcha un proyecto de restructuración de la Matriz Productiva, que ha planteado políticas y leyes en favor del desarrollo y la mejora de la sociedad (Secretaría Nacional de Planificación y Desarrollo (Senplades, 2013). Dentro de esta visión de país, según el Ministerio de Coordinación de la Producción, Empleo y la Competitividad (MCPEC, 2013), se busca el "desarrollo territorial con identidad cultural"; $\mathrm{y}$, siendo la artesanía un sector priorizado por el gobierno, se esboza un panorama positivo para su desarrollo y crecimiento.

Las políticas de fomento de la producción (MCPEC, 2013), políticas culturales ${ }^{1}$, la ley $\operatorname{artesanal}^{2}$ y la creación de la Universidad de las Artes ${ }^{3}$ generan un panorama fértil para el desarrollo de sectores productivos y artesanales a través de proyectos y de la investigación, esto abre caminos hacia la integración del diseño como detonante creativo para la mejora y elaboración de productos innovadores.

Que la artesanía pertenezca a un creciente sector con mucho potencial económicoproductivo como es la ICC, sumado a la perspectiva ecuatoriana de promover el emprendimiento, facilita el desarrollo de la artesanía como sector estratégico; pero esto hace necesario buscar mejoras en el producto y contexto donde se desarrolla la actividad y sus actores. Jones (1982, p.13) identifica al artesano como "el primer iniciador del cambio en las cosas hechas por el hombre", pero también explica la falencia del proceso artesanal en no desarrollar códigos sistemáticos de transmisión de información que permitan replicar el trabajo artesanal.

\footnotetext{
1 Políticas para una Revolución Cultural (2011), se lo puede encontrar en: http:/www.culturaypatrimonio.gob.ec/wp-content/uploads/downloads/2013/04/Revolucion-Cultural-2011Folleto.pdf

2 Ley de Defensa del Artesano, se lo puede encontrar en: http://issuu.com/jnda2012/docs/ley_de_defensa_del_artesano

${ }^{3} \mathrm{http}: / /$ www.uartes.edu.ec/
} 
Esta falencia se traduce en la carencia de procesos metódicos, técnicos y conceptuales que puedan ser documentados como es un plano técnico o lineamientos conceptuales del producto, además, la artesanía ecuatoriana en algunos casos se enfoca en lo popular, arraigado en procesos ancestrales, mientras que en otros, en procesos semi industrializados; esto dificulta la generación de nuevos productos debido a limitaciones por la ausencia de información o profesionales que generen propuestas creativas e innovadoras.

\subsection{Situación de la artesanía en la Provincia de Tungurahua}

La provincia de Tungurahua se encuentra en la región montañosa andina y geográficamente en el centro del país; dentro de la división territorial estratégica planteada por el Gobierno Nacional, Tungurahua se ubica en la Zona 3 (Figura 1). La provincia se ha mantenido pujante con la producción agrícola, artesanal, turismo, industria metalmecánica, industria textil, el comercio y una gran variedad de medianas y pequeñas industrias de diferentes sectores ${ }^{4}$. Esto hace que la provincia adquiera un potencial frente a políticas que pretenden apoyar a regiones que no son polos de desarrollo ${ }^{5}$, además de apoyar la generación de conocimiento a través de la investigación.

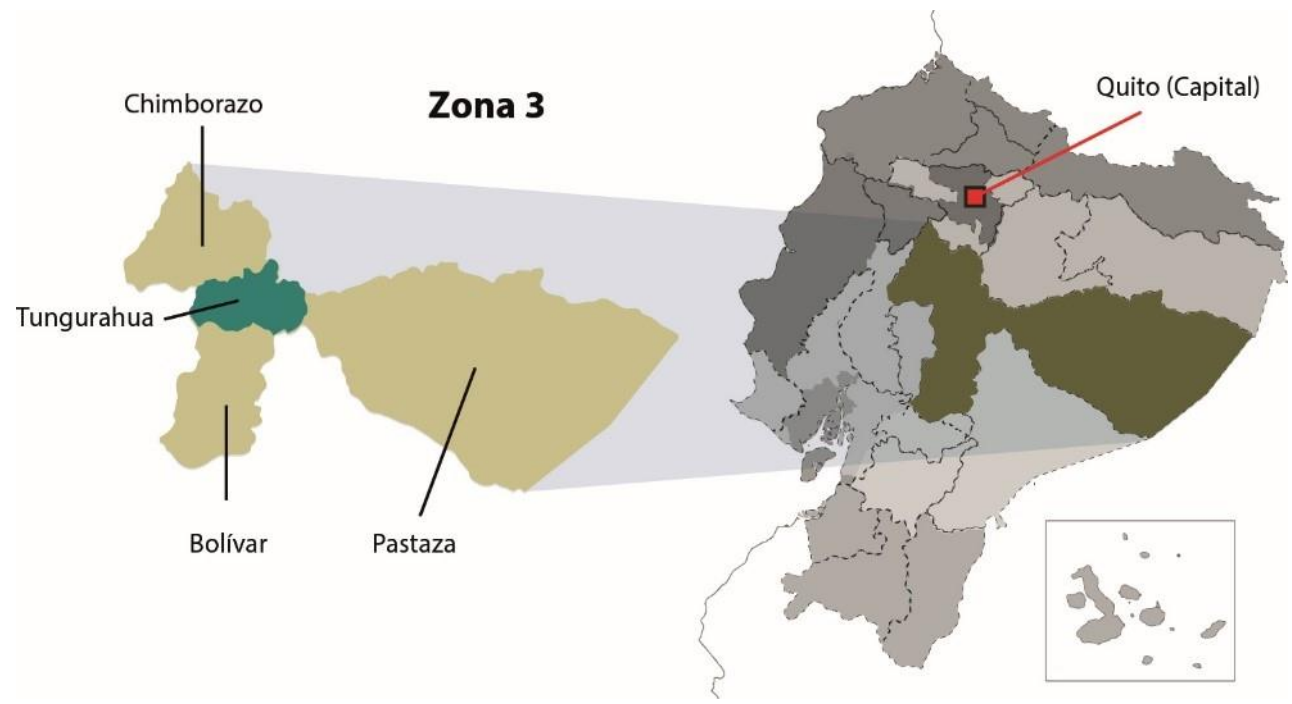

Fig. 1 Ubicación Geográfica de la Provincia de Tungurahua-Ecuador (2017).

\footnotetext{
${ }^{4}$ Una descripción de estos sectores está presente en LA AGENDA TUNGURAHUA DESDE LA VISIÓN TERRITORIAL, Gobierno Provincial de Tungurahua (2012) de la Zona 3 de Ecuador, [archivo digital], se lo puede encontrar en: http://sni.gob.ec/planes-de-desarrollo-y-ordenamiento-territorial

${ }^{5}$ Los polos de desarrollo se concentran en las ciudades: Quito, Guayaquil y Cuenca (Senplades, 2013, p.89)
} 
La producción textil y tejidos autóctonos están entre las actividades artesanales más importantes y de amplio alcance en Ecuador ${ }^{6}$, siendo Tungurahua un referente importante de esta actividad, y la provincia con mayor desarrollo productivo en el centro del país. (MCPEC, 2011 y 2013)

\subsection{El Diseño en la productividad}

El diseño toma fuerza como parte esencial del sector productivo, ya que el diseño marca pautas y conceptos que guían proyectos y los lleva adelante; muchos autores, entre ellos: Bonsiepe (2012), Best (2009), Cox (2005), Finizio (2002), Jones (1982), Montaña (1989) y Lecuona (2007) concuerdan la necesidad del diseño de tomar partida de los procesos en las empresas para integrarse como eje estratégico de desarrollo social, productivo y la innovación.

Para Best (2009, p.6), “el diseño desempeña un papel muy importante a la hora de dar forma y generar nuevos productos, sistemas y servicios que respondan a las diversas condiciones y oportunidades del mercado"; mientras que Lecuona $(2007$, p.5) plantea que el diseño "debería considerarse como proceso multidisciplinar, donde intervienen varios especialistas de áreas distintas de la empresa al objeto de planificar e introducir nuevos productos en el mercado", esto permite conformar equipos de profesionales y artesanos que procesen ideas y conceptos, manteniendo una retroalimentación de conocimiento y experiencias.

Según Lecuona (2007, p.8) "el diseño para ser efectivo dentro de la empresa debe integrarse colaborando e influyendo en todos los niveles de decisión del esquema organizativo"; este trabajo en conjunto con la empresa se amplía a todas las áreas de acción del diseño como: Gráfico, Moda, Multimedia, Producto, etc.; además de adentrarse en el proceso mismo de la empresa. Para Best (2009, p.16) "en la actualidad, el diseño se centra en mejorar las experiencias y el servicio de atención a los clientes, así como en mejorar las funciones y estrategias de reducción de residuos de las empresas", pudiendo abarcar acciones estratégicas no previstas anteriormente en la industria artesanal.

En la empresa el diseño cumple la función creativa y proyectual en el desarrollo productivo; en ese sentido, Cox (2005, p.3), afirma "una mayor creatividad es la clave para una mayor productividad, ya sea por medio de productos y servicios de mayor valor, mejores procesos, un marketing más eficaz, las estructuras más simples o mejor uso de las habilidades de las personas" esto hace que las empresas se proyecten a nuevos mercados e incluyan valor agregado a su oferta; según Kootstra (2009, p.9) "las empresas que invierten

\footnotetext{
${ }^{6}$ El Banco Central del Ecuador (BCE) señala que este sector es uno de los más antiguos, manteniendo gran importancia con más de 22.000 artesanos (p.158). Fuente: BCE (1985). Artesanía y Modernización del Ecuador, [en línea]. Quito. Disponible en: http://repositorio.iaen.edu.ec/handle/24000/589
} 
en diseño tienden a ser más innovadoras y rentables, y crecen más rápido que las empresas que no lo hacen"; así mismo, Bonsiepe (2012, p.248) explica que "el diseño puede verse como uno de los indicadores de la competitividad que, a su vez, está directamente vinculada a la globalización”. Todos estos factores conjugados plantean una visión más amplia del diseño y su aporte en sectores productivos a cualquier nivel.

\subsection{Definiendo la problemática}

El diseño se posiciona como alternativa al desarrollo, no solo por ser una disciplina proyectual encaminada al desarrollo conceptual, metódico y creativo de diversos productos tangibles e intangibles, sino también, por generar servicios asociados a estos. El diseño también se centra en proyectos multidisciplinarios y el desarrollo de la innovación e investigación. El diseño con su experiencia en la gran industria puede enfocarse en sectores creativos de menor escala como el artesanal para poder trasladar experiencias y estrategias que fortalezcan y diversifiquen su producción.

La problemática se centra en la pérdida del valor competitivo que genera barreras hacia nuevos mercados por la ausencia de una identidad clara, limitaciones en los procesos y productos enfocados hacia el suvenir o turismo; ante esto, surge la interrogante sobre qué criterios de competitividad se requieren para generar valor en la producción artesanal textil de la Provincia de Tungurahua-Ecuador.

La respuesta a la interrogante se centra en identificar los factores estructurales del ADN del Diseño, que permitirá determinar atributos y características diferenciadoras que brinden un valor competitivo para su ingreso a nuevos mercados; para esto, se debieron cumplir objetivos como: identificar factores clave que definen la naturaleza de la artesanía y su relación con el sector cultural y creativo; Elaborar un diagnóstico de la situación en base a políticas de estado enfocadas al desarrollo de emprendimientos artesanales; Identificar factores de diseño que permitan el nexo entre artesanía, industria e innovación; y por último, plantear una estructura de $\mathrm{ADN}$ que potencialice la competitividad artesanal.

\section{Materiales y métodos}

Para lograr los resultados se rastreó una amplia base documental que ofreciera información actualizada y válida, que pudiera ser contrastada y que sea fácil de conseguir.

\subsection{Definición metodológica}

La investigación tiene un enfoque cualitativo constructivista, que permite crear una realidad de la industria artesanal en base a factores determinados de la sociedad, la cultura y el ámbito productivo. Se buscó construir una percepción entre diseño y artesanía partiendo de 
ideas y experiencias existentes para generar un enfoque a la situación particular ecuatoriana, pero con una visión global.

La investigación constó de dos etapas:

a) Análisis de literatura, búsqueda de definiciones para la comprensión del panorama actual como punto de partida de la investigación. El contexto actual y global se definió analizando diferentes posturas de expertos e instituciones, además de propuestas gubernamentales.

b) De la diversa documentación encontrada se identificó referentes importantes a nivel local (Ecuador) y a nivel global (mundial):

- Comisión Europea, Green Paper "Liberar el potencial de las industrias culturales y creativas." (2010);

- UNESCO, "Políticas para la creatividad. Guía para el desarrollo de las industrias culturales y creativas" (2010);

- Ecuador “Agenda de Transformación Productiva” [ATP] (2013)

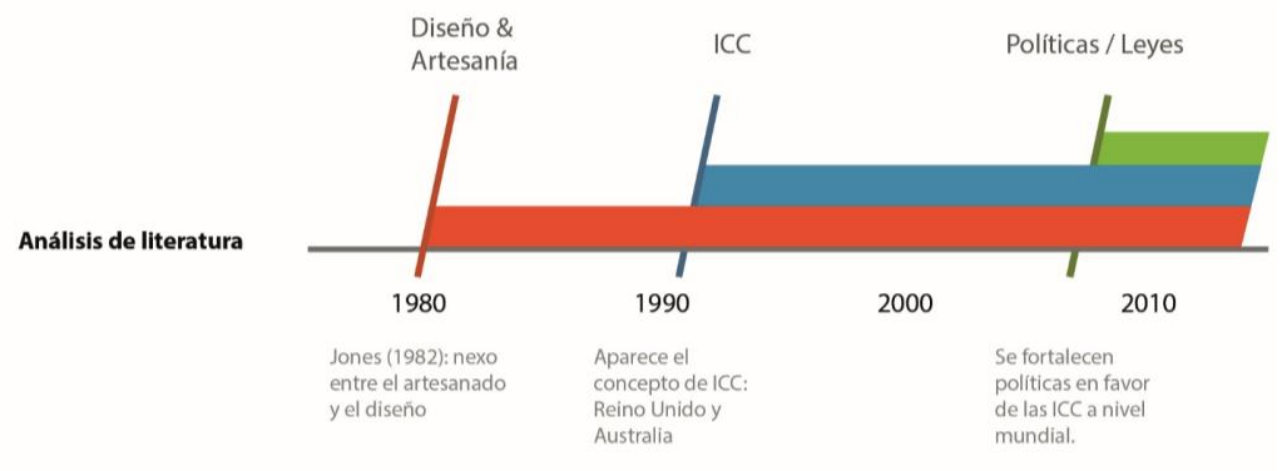

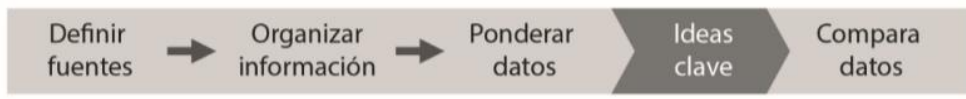

Fig. 2 Etapas de investigación (2017).

Los factores se definieron al tomar datos e ideas clave de los documentos mencionados para buscar relaciones y características comunes; en este punto se aplicó el análisis de contenidos a partir de los métodos: investigación de ideas y de 
evaluación planteados por Jones (1982); se empleó la lluvia de ideas y la clasificación y ponderación de información cualitativa.

La clasificación y ponderación permitió identificar ideas o términos con mayor presencia o incidencia en el discurso de cada documento y se asignaron referentes numéricos o literales a cada dato. Posteriormente se tradujo la información en ideas clave de fácil comprensión, esto sirvió para buscar su representatividad y coincidencias entre documentos. Se buscó coincidencias a nivel internacional para luego compararlas a nivel local.

\section{Resultados}

Se utilizaron tablas y gráficos para organizar y representar datos de las relaciones y coincidencias de forma lógica y dinámica.

\subsection{Caracterización de los componentes de las ICC}

Se partió con el documento "Políticas para la creatividad. Guía para el desarrollo de las industrias culturales y creativas" UNESCO $(2011)^{7}$; se buscó factores de la ICC y su relación con la productividad y entorno, dando como resultante ideas clave ${ }^{8}$ (Figura 3). La relación entre ideas clave y su importancia con las seis áreas de intervención para el desarrollo de las ICC son una base común para el resto de la investigación.

\footnotetext{
${ }^{7}$ Este documento es una sólida fuente de información que agrupa muchos referentes y a la vez es metódico en el planteamiento de acciones y estrategias para el desarrollo de las ICC.

${ }^{8}$ Cada palabra clave se planteó tratando de englobar diferentes ideas encontradas en la guía, que por su cantidad debieron ser ponderadas, agrupadas $\mathrm{y} / \mathrm{o}$ redefinidas.
} 


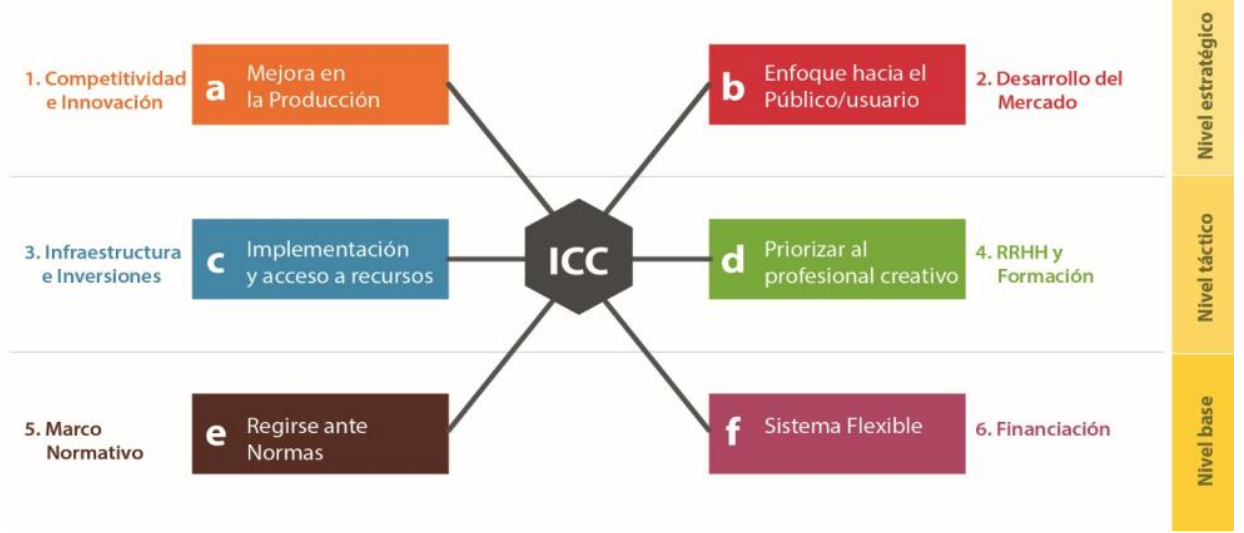

Fig. 3 Relación entre palabras clave con las 6 áreas de intervención de las ICC (2017)

La gráfica presenta tres grupos, (1) Nivel base, que de apertura a nuevos emprendimientos, y apoye y proteja a los existentes; (2) Nivel estratégico, permitiría establecer procedimientos y acciones puntuales para aumentar su productividad e innovación; (3) Nivel táctico, se encargaría de disponer recursos y personal para lograr objetivos de desarrollo para la ICC.

Con el resultado (Figura 3), se buscó relacionar áreas de acción (UNESCO) con los tres factores clave planteados por la Comisión Europea en su documento "Green paper" (2010): (1) Diversidad Cultural, (2)Globalización y (3) Transición al Entorno Digital; a fin de lograr una lógica de criterios relacionados.
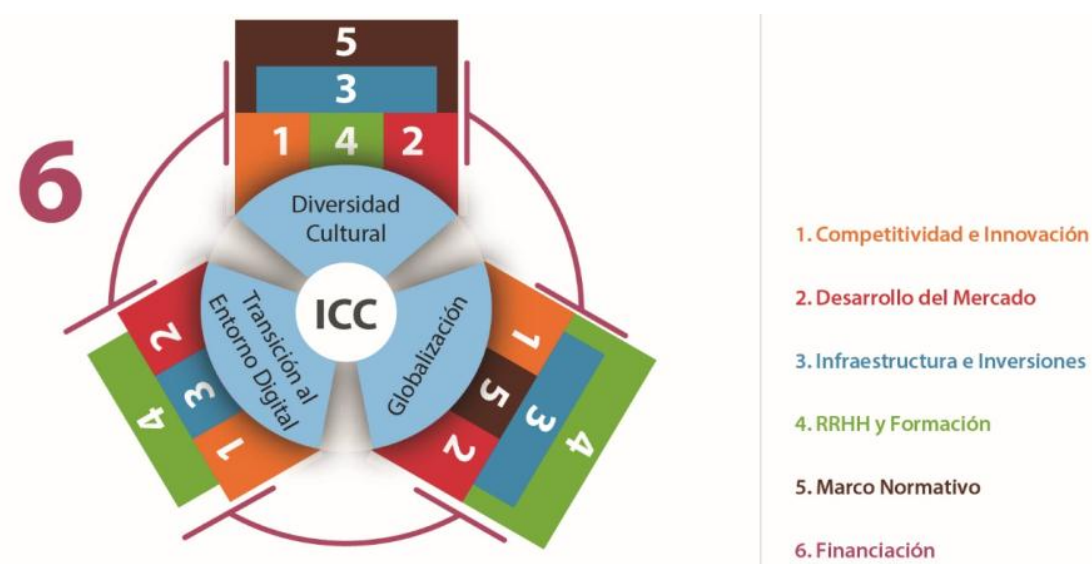

Fig. 4 Relación entre factores clave (Green paper) y áreas de intervención (Adaptado de COMISIÓN EUROPEA, 2010; $y$ UNESCO, 2011). 
La Figura 4, presenta relaciones entre factores clave de la Comisión Europea y las áreas de intervención de UNESCO; esto se plantea tomando en cuenta la financiación como base común para toda acción en el panorama de la ICC.

En los tres factores clave se determinó una relación directa y constante con el eje estratégico (Figura 3) encontrado en el planteamiento de UNESCO; siendo variables los otros elementos de las áreas de intervención.

El factor Diversidad Cultural se reconoce como la razón de ser de esta industria, que vinculada con la creatividad, permite construir proyectos y emprendimientos con rasgos propios de identidad; el profesional creativo toma principal importancia, y para su desarrollo se necesita inversión en infraestructura para su capacitación y mejora productiva, además de un marco normativo de respaldo. El factor Globalización se centra en un marco legal común y globalizado, es decir, leyes que apoyen a profesionales creativos en cualquier lugar del planeta, generando igualdad de condiciones, competitividad y protección de sus creaciones en un mercado global, para esto se requiere profesionales competentes y aptos para desenvolverse en diferentes localidades, situaciones, con conocimientos de nuevas tecnologías y procesos. El factor Transición al Entorno Digital pone en valor la necesidad de estar al día con la tecnología, ser parte activa de las redes sociales, el uso de dispositivos móviles, video conferencias y demás formas de comunicación online. La inversión en infraestructura para el acceso a estos servicios, así como el fácil acceso para la adquisición de equipos especializados son el eje que tomar en cuenta, así también, se necesita personal capacitado en el manejo de equipos y en cómo sacar partido de estas tecnologías.

\subsection{Comparativa con el panorama productivo ecuatoriano}

En la siguiente etapa se identifica posibilidades de desarrollo de la ICC en base al entorno actual ecuatoriano planteado en la ATP (2013) y los factores analizados anteriormente en esta investigación. La ATP pretende reorganizar y desarrollar el sistema productivo nacional en base a lineamientos del Plan Nacional del Buen Vivir.

Los referentes para esta comparativa son los 8 pilares de la ATP, de los que se derivan cuatro principios rectores: ética con los trabajadores, con la comunidad, con el Estado y con el medio ambiente. También se toma en cuenta políticas transversales, comunes a los sectores económicos y políticas Sectoriales ${ }^{9}$ para el desarrollo estratégico del país.

\footnotetext{
${ }^{9}$ Las políticas sectoriales se vinculan con: Ministerio de Agricultura, Ganadería, Acuacultura Y Pesca (MAGAP); Industrias y Productividad (MIPRO) y de Turismo (MINTUR); para la investigación se toman las políticas desarrolladas por MIPRO y MINTUR, ya que son ministerios que pueden favorecer e impulsar las ICC en Ecuador.
} 


\subsubsection{Comparativa (A)}

La comparativa entre los 8 pilares con factores clave y áreas de intervención de la ICC (Figura 4.) determinó que los pilares tienen mayor incidencia en el factor Transición al entorno Digital, siendo el talento humano, la democratización de recursos, crecimiento verde, competitividad e innovación, los que respaldan su integración y desarrollo; los factores Diversidad cultural y Globalización se relacionan en menor medida con los mismos pilares, pero debe sumarse la cultura e imagen del país como referente característico de estos dos factores.

Con relación a las seis áreas de intervención planteados por UNESCO (Figura 5), se presenta una jerarquía en función a la concentración de puntos, donde se identifica mayor incidencia en Infraestructura e inversiones, dando una pauta sobre la importancia de esta área como motor impulsor. Otras dos áreas destacadas por su concentración son: Competitividad e Innovación, y Desarrollo del Mercado, estos son concordantes con su presencia y valor estratégico identificado anteriormente (Figuras 3 y 4 )

Otros puntos clave son: medio ambiente, conocimiento, innovación e igualdad; que resultan de interconexiones conceptuales que parten de las agrupaciones de los pilares de la ATP.

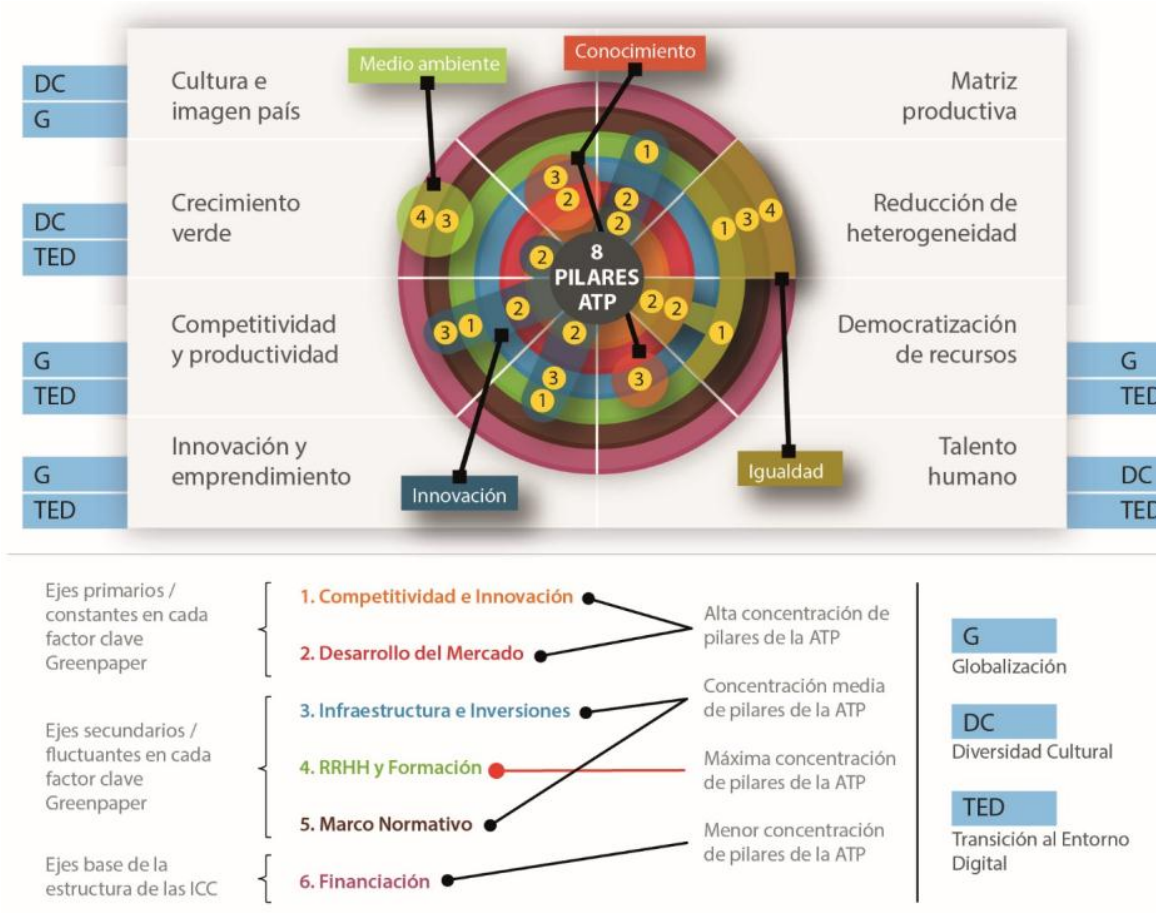

Fig. 5 Concordancia de los ocho pilares con las ICC (Adaptado de COMISIÓN EUROPEA, 2010; UNESCO, 2011; y ATP 2013). 


\subsubsection{Comparativa (B)}

En la segunda comparativa se analizó relaciones entre políticas transversales, sectoriales y las provenientes de los Principios que conforman la ATP y los asuntos importantes a resolver para el desarrollo de las ICC planteados por la Comisión Europea:

- Nuevos espacios para la experimentación,

- Innovación y emprendimiento,

- Estandarizar las habilidades necesarias para las ICC,

- Dimensión local y regional,

- Acceso a la financiación,

- Movilidad y circulación,

- Dimensión internacional, y

- Hacia una economía creativa: Los efectos indirectos de las ICC.

La comparativa identificó planteamientos e intenciones sólidas que favorecerían a la ICC por su enfoque moderno y proyección a nuevos emprendimientos; además del enfoque a profundos cambios socioculturales y una concepción global de mercados y necesidades a cubrir.

Los temas de educación, innovación, y nuevos emprendimientos se presentan estrechamente relacionados a la la calidad, también se apoya la salida de productos a mercados extranjeros y acceso al financiamiento que posibilite esto. La búsqueda de equilibrio en sectores productivos hace que se planteen apoyos a sectores artesanales microempresas y Pymes para generar competitividad; otros temas relevantes propuestos en la ATP son la Sostenibilidad Ambiental y Eficiencia energética, situación que genera un enfoque social importante en cuanto a energías renovables y materiales amigables con el medio ambiente. Un aspecto negativo dentro de este análisis es la ausencia del término diseño como un componente de desarrollo de la industria, ya que, desde esta disciplina se puede apoyar intereses productivos, ambientales, innovadores y creativos al ser temáticas muy apegadas al diseño.

La Figura 6 presenta la estructura de relación y jerarquías de los asuntos importantes a resolver para el desarrollo de las ICC, también se propone al diseño como eje de desarrollo de la industria. 


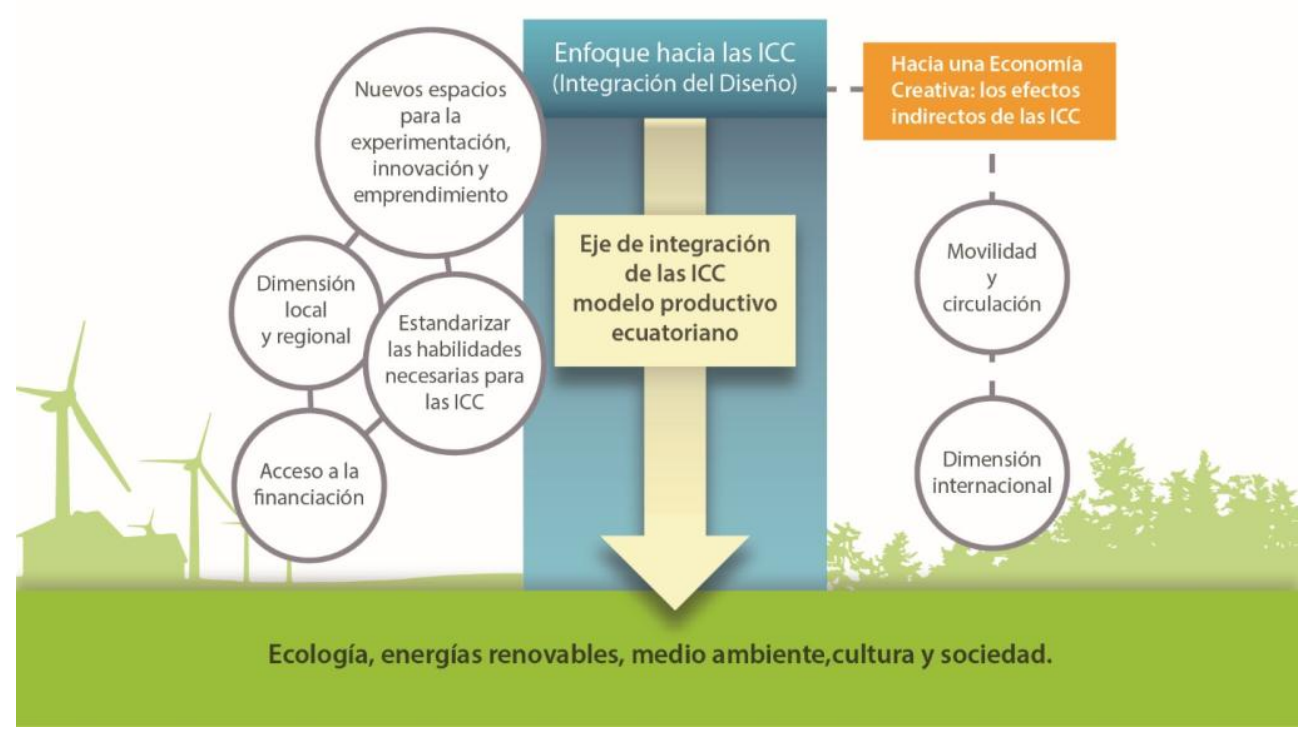

Fig. 6 Integración del diseño en el modelo productivo ecuatoriano de las ICC (Adaptado de COMISIÓN EUROPEA, 2010; UNESCO, 2011; y ATP, 2013).

\section{Propuesta}

Se proponen las siguientes guías para el desarrollo del de ADN del diseño de la artesanía textil de Tungurahua:

1. Apoyo a la producción ancestral artesanal mediante innovaciones acordes a su naturaleza, respetando sus características diferenciadoras propias del saber hacer artesanal.

2. Innovación mediante la integración de sectores artesanales con industrializados; fusión de ideas y creación de nuevos productos a través del diseño.

3. Cimentar bases de cambio en los modelos productivos y uso de la creatividad para el desarrollo productivo.

4. Reforzar la calidad en educación e infraestructura para promover el desarrollo profesional en áreas vinculadas a la ICC y el diseño.

5. Las acciones tomadas en favor de la innovación y desarrollo de nuevos productos deben basarse en simbiósis entre profesionales, productores y artesanos.

6. Plantear proyectos conjuntos enfocados en la internacionalización de productos y alcanzar beneficios que individualmente no es posible acceder.

7. Identificar sectores potenciales del ámbito cultural y creativo acordes a la realidad nacional, entornos geográficos y sociales para crear nuevos polos de desarrollo.

8. Fomentar una conciencia social, cultural y ambiental basada en: respeto, justicia y emprendimiento. 
A partir de estas ideas, se plantea a la creatividad como impulsora productiva dentro del entorno artesanal ecuatoriano, abriendo caminos para que profesionales y sectores de la ICC puedan desarrollarse y apoyen más sectores de la matriz productiva ecuatoriana. Como segundo aspecto, el diseño debe ubicarse como eje de desarrollo social, cultural y productivo, en un entorno compuesto por normas, leyes, desarrollo tecnológico e investigativo, con profesionales capacitados y de producción creativa; donde el diseño se integre y aporte a través de la creación y mejora de productos y servicios enfocados en la cultura y tradiciones como valor agregado, permitiendo generar experiencias en la sociedad y consumidores.

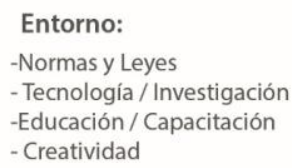

Fig. 7 El Diseño como eje de productivo (2017)

Como tercer aspecto se identifica la relación entre artesanía y otros sectores de la ICC (Figura 8); UNESCO identifica tres grupos: Herencia cultural, Creatividad y medios, y Creaciones funcionales. La artesanía se encuentra en el grupo de Creatividad y medios con otros sectores como artes visuales, medios, prensa, entre otros; donde se centran en la forma creativa que el hombre proyecta sus destrezas en productos y servicios a través de habilidades propias o adquiridas y por medio de instrumentos o procesos que pueden ser o no industrializados. 


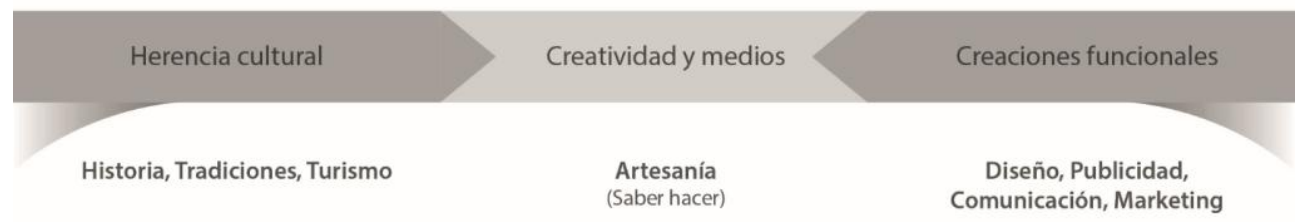

Fig. 8 Apoyo a la artesanía desde otros sectores de la ICC.

Otros grupos pueden apoyar a la artesanía por sus características particulares; así, la herencia cultural tiene un sentido intangible, histórico y ancestral relacionado con la interacción social, cosmovisión, representaciones y materias prima de la producción artesanal. El grupo de las creaciones funcionales por su trabajo conceptual y metódico permite llegar a soluciones mediante la investigación, procesos y la experimentación; este grupo se considera esencial en este proyecto ya que puede fortalecer el trabajo artesanal llevándolo a nuevas dimensiones creativas en base a la innovación. Esta interacción podría diversificar la oferta artesanal y vincularla con servicios provenientes de sectores complementarios como el turismo.

\subsection{ADN del diseño de la industria artesanal ecuatoriana}

Se han identificado cinco genes del ADN que responden a características propias de la ICC y son coincidentes con la ATP:

\subsubsection{Sociedad y su Entorno:}

Una conciencia colectiva comprometida con la creación de una identidad propia basada en formas de actuar, de pensar y en la historia; esta visión no debe dejar de lado al mundo globalizado para su desarrollo.

\subsubsection{Valor Cultural y Creativo:}

La cosmovisión del país o región contiene factores que dan origen y una concepción de las expresiones y la artesanía desarrollada; los elementos materiales e inmateriales construyen los productos y del valor cultural

\subsubsection{Diseño:}

Desde sus áreas: diseño de productos, moda, empaque, publicitario, identidad corporativa, etc., se de paso al ingreso a nuevos mercados, una mejor oferta y propuestas originales.

\subsubsection{Estructura de Empresa:}


El interés del estado por un cambio en el aparato productivo permite generar nuevas visiones que dejen de lado estructuras caducas e integren soluciones a problemáticas locales y globales en todo nivel.

\subsubsection{Estrategia:}

- Enfoque social y hacia el consumidor con mente abierta al cambio.

- Valor cultural y creativo como factor de generación de identidad propia y al servicio de la productividad.

- Diseño como eje en el desarrollo productivo centrado en la $\mathrm{I}+\mathrm{D}+\mathrm{i}$

- Nueva concepción de empresa con visión global y pensamiento local.

A su vez, los genes tienen las siguientes características:

1. Sociedad y su Entorno. Ejes claves que intervienen en la definición de la identidad propia: público objetivo, percepción de la sociedad, conciencia social y medio ambiental.

2. Valor Cultural y Creativo: Intangible que otorga diferenciación a cada producto desarrollado como expresión del entorno y cosmovisión del lugar de procedencia.

3. Diseño: Desarrollo de la $\mathrm{I}+\mathrm{D}+\mathrm{i}$ desde diversos campos especializados para generar nuevos productos y procesos innovadores con apoyo de universidades y centros de investigación.

4. Estructura de Empresa: Integración en la empresa de los elementos que conforman y definen al emprendimiento cultural y creativo.

5. Estrategia: Filosofía de Diseño para lograr que la esencia del bien o servicio más la esencia de su origen y razón de ser sean valorados por el consumidos en un mercado global.

La estructura final se presenta como un conjunto de genes que trabajan interconectados; cada gen tiene un factor principal que da un valor único y caracteriza el entorno artesanal textil de la provincia de Tungurahua (Figura 9). 


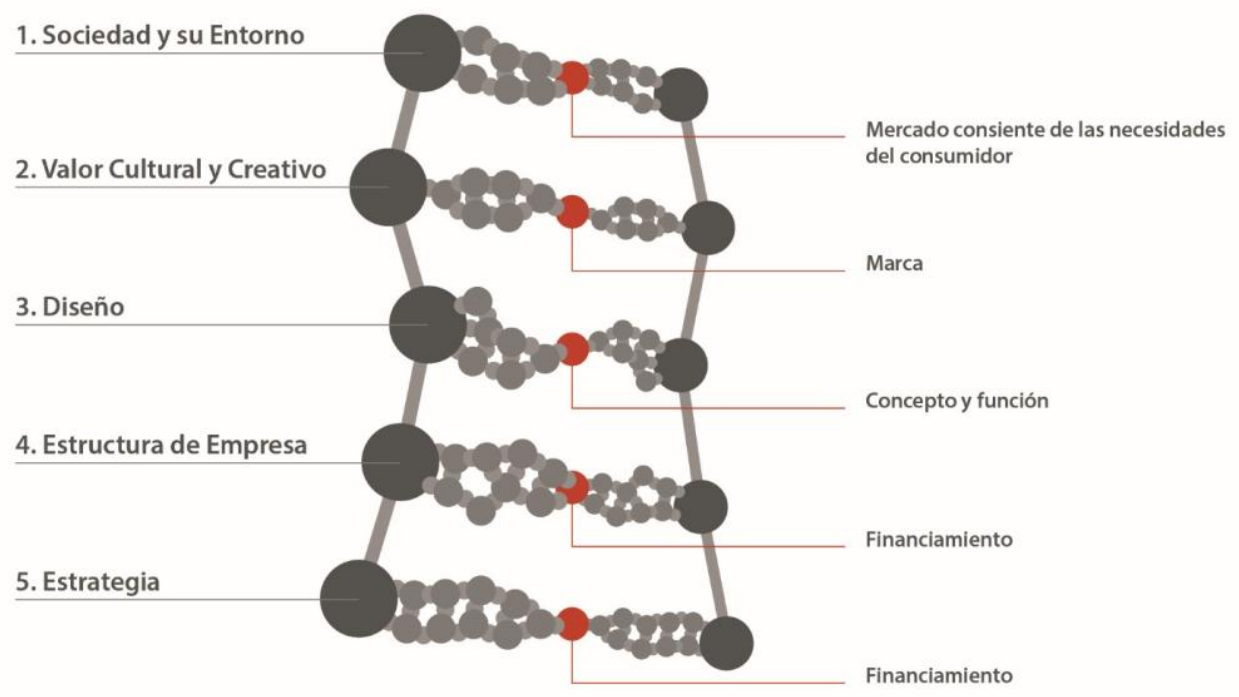

Fig. 9 Estructura del ADN del diseño de la artesanía (2017).

Además de los elementos presentados (Figura 9), se plantean factores generales en cada gen (Figura 10).

\section{Factores generales del ADN}

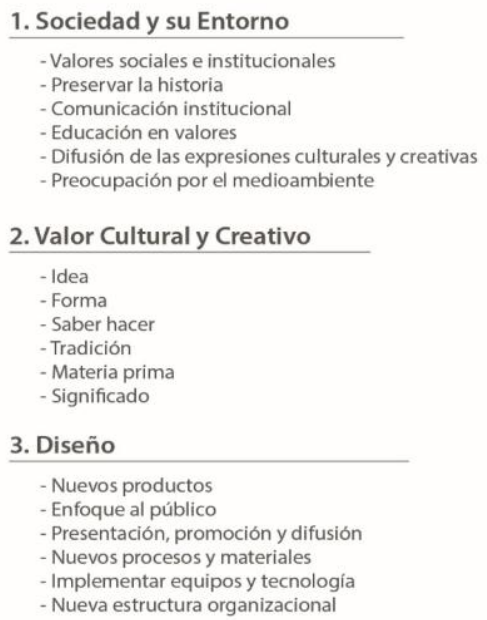

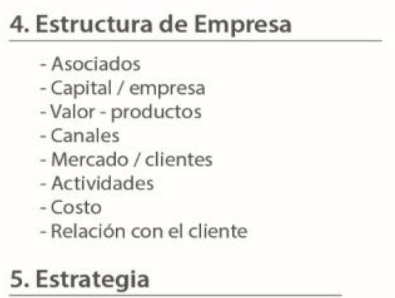

- Recopilar el saber hacer ancestrales

Producto aumentado

- Nuevo concepto y función en productos

- Enfoque a públicos y sus necesidades

- Preservar fuentes de materia prima

- Experiencia incrementada (preservar la cadena de experiencias)

- Conciencia medioambiental

- Uso de formas de cobro electrónico

- Fomento a las redes

Fig. 10 Factores generales del ADN del diseño de la artesanía (2017). 


\section{Conclusiones}

Se debe cubrir necesidades específicas de la ICC mediante acciones estratégicas provenientes de instituciones públicas que fortalezcan y promuevan la innovación y la calidad de sectores con un perfil cultural y creativo; teniendo en cuenta sectores de mayor potencial productivo o con trayectoria, y primando un enfoque adaptado al entorno sociocultural de la provincia.

Para el desarrollo de la ICC se necesita el acceso a la financiación como punto de partida, así también, la comprensión de la dimensión local y global permitiría generar una mentalidad abierta a nuevos mercados por parte de artesanos y creativos, esto se conjuga también con la necesidad de profesionales y técnicos que trabajen conjuntamente para el desarrollo de la industria.

Se debe evolucionar al desarrollo de espacios de apoyo a la experimentación, innovación e incubación de emprendimientos basados en nuevos modelos de negocio; situación que puede solventarse desde centros educativos y clústeres enfocados en la ICC; y es en este punto donde el diseño toma fuerza, ya que, los sectores productivos se verían beneficiados gracias al impulso creativo del profesional de diseño y las diferentes áreas de conocimiento que abarca esta disciplina.

\section{Referencias}

Best, K. (2009). Management del diseño. Barcelona: Parramón Ediciones.

Bonsiepe, G. (2012). Diseño y crisis. Valencia: Campgràfic.

Comisión Europea (2010). LIBRO VERDE, Liberar el potencial de las industrias culturales y creativas, [en línea]. Bruselas. http://eur-lex.europa.eu/LexUriServ/ LexUriServ.do?uri=COM:2010:0183:FIN:ES:PDF

Cox, G. (2005). Cox Review of Creativity in Business: building on the UK's strengths [en línea]. Londres: The Colourhouse. http://grips-public.mediactive.fr/ knowledge_base/view/349/cox-review-of-creativity-in-business-building-on-the-uksstrengths/

Finizio, G. (2002). Design \& Management. Milano: Skira.

Jones, C. (1982). Métodos de Diseño (3a. ed.). (Trad. M. López; E. Riambau). Barcelona: Gustavo Gili. (Original en inglés, 1970)

Kootstra, G. (2009). The incorporation of design management in today's business practices. Rotterdam: INHOLLAND. http://www.bcd.es/site/unitFiles/2585/DME_Survey09darrera\%20versi\%C3\%B3.pdf 
Lecuona, M. (2007). Manual sobre Gestión de Diseño para empresas que abren nuevos mercados. Barcelona: BCD, Barcelona Centro de Diseño.

Ministerio de Coordinación de la Producción, Empleo y la Competitividad [MCPEC]. (2011). Agendas para la Transformación Productiva Territorial: Tungurahua. Quito. http://www.produccion.gob.ec/wp-content/uploads/downloads/2013/02/AGENDATERRITORIAL-TUNGURAHUA.pdf

Ministerio de Coordinación de la Producción, Empleo y Competitividad [MCPEC] (2013). Agenda para la TRANSFORMACIÓN PRODUCTIVA. Quito. http://www.produccion.gob.ec/wpcontent/uploads/downloads/2012/07/Agenda_Productiva[1].pdf

Montaña, J. (1989). Cómo diseñar un producto. Madrid: IMPI.

Secretaría Nacional de Planificación y Desarrollo [Senplades]. (2013). Plan Nacional para el Buen Vivir 2013-2017. Quito, Ecuador. http://documentos.senplades.gob.ec/Plan\%20Nacional\%20Buen\%20Vivir\%2020132017.pdf

United Nations Conference on Trade and Development [UNCTAD]. (2010). Economía Creativa: Una opción factible de desarrollo. United Nations. http://unctad.org/es/Docs/ditctab20103_sp.pdf

United Nations Educational, Scientific and Cultural Organization [UNESCO]. (2011). Políticas para la creatividad. Guía para el desarrollo de las industrias culturales y creativas. Argentina: Gr fica Latina. http://www.unesco.org/new/fileadmin/MULTIMEDIA/HQ/CLT/images/UNESCOCulturala ndCreativeIndustriesguide_01.pdf

United Nations Educational, Scientific and Cultural Organization [UNESCO]. (2013). INFORME SOBRE LA ECONOMÍA CREATIVA 2013 EDICIÓN ESPECIAL. México. http://www.unesco.org/new/en/culture/themes/creativity/creative-economy-report-2013special-edition 